\title{
A verdade e a interpretação poética na psicanálise lacaniana
}

\author{
Ingrid Porto de Figueiredo
}

\begin{abstract}
Resumo
Este artigo tem como objetivo abordar a noção de verdade em sua articulação com a interpretação poética na psicanálise lacaniana. A proposta da operação analítica pela via da interpretação poética com o uso da função poética da linguagem visa ao sentido e vai contra a significação fálica, de modo a questionar o valor de verdade presente na fantasia fundamental. Por isso, Lacan recorreu à escrita poética chinesa e ao sopro do vazio mediano por fazer ressoar outra coisa. Trata-se de circunscrever uma verdade não-toda e poética a partir da tensão entre som e sentido na articulação entre o matema e o poema.
\end{abstract}

\section{Palavras-chave:}

Verdade; Interpretação poética; Sentido; Significação; Escrita poética chinesa; Real.

\section{The truth and the poetic interpretation in the Lacanian psychoanalysis}

\begin{abstract}
This article aims to address the notion of truth in relation to the poetic interpretation in the Lacanian psychoanalysis. The proposal of the analytical operation via the poetic interpretation through the use of the poetic function of language aims at the sense and goes against the phallic signification, in order to question the value of truth present in the fundamental fantasy. For that reason, Lacan resorted to the Chinese poetic writing and to the blow of the median emptiness for making something else resound. It is a matter of circumscribing a truth that is poetic and not-whole, taken from the tension between sound and sense, in the articulation between the matheme and the poem.
\end{abstract}

\section{Keywords:}

Truth; Poetic interpretation; Sense; Signification; Chinese poetic writing; Real. 


\title{
La verdad y la interpretación poética en el psicoanálisis lacaniano
}

\begin{abstract}
Resumen
Este artículo tiene como objetivo abordar la noción de verdad en la articulación con la interpretación poética en el psicoanálisis lacaniano. La propuesta de la operación analítica por la vía de la interpretación poética por el uso de la función poética del lenguaje apunta al sentido y va en contra de la significación fálica, de modo a cuestionar el valor de verdad presente en la fantasía fundamental. Por eso Lacan recurrió a la escritura poética china y al soplo del vacío mediano, por hacer resonar otra cosa. Se trata de circunscribir una verdad no toda y poética a partir de la tensión entre sonido y sentido, en la articulación entre el matema y el poema.
\end{abstract}

\section{Palabras clave:}

Verdad; Interpretación poética; Sentido; Significación; Escritura poética china; Real.

\section{La vérité et l'interprétation poétique dans la psychanalyse lacanienne}

\begin{abstract}
Résumé
Cet article a pour but d'aborder la notion de vérité dans son articulation avec l'interprétation poétique dans la psychanalyse lacanienne. La proposition de l'opération analytique via l'interprétation poétique avec l'utilisation de la fonction poétique du langage vise le sens et va à l'encontre de la signification phallique, de façon à interroger la valeur de vérité présente dans le fantasme fondamental. Pour ce faire, Lacan a fait appel à l'écriture poétique chinoise et au souffle du vide médian pour faire résonner quelque chose d'autre. Il s'agit de repérer une vérité pastoute et poétique, à partir de la tension entre le son et le sens, dans l'articulation entre le mathème et le poème.
\end{abstract}

\section{Mots-clés :}

Vérité ; Interprétation poétique ; Sens ; Signification ; Écriture poétique chinoise ; Réel. 
Iniciaremos com a interrogação de Gianesi e Ramos (2015), a que questiona se o saber $\left(\mathrm{S}_{2}\right)$ situado no lugar da meia-verdade no discurso analítico seria um saber poético. A resposta parece ser afirmativa, pois eles destacam que há nesse discurso uma operação de suspensão de sentido (Sinn) e de um saber fazer com o duplo sentido a partir de uma hesitação entre sentido e som, de modo a produzir uma ambiguidade do referente ou significação (Bedeutung) a partir da função poética — postulada por Jakobson (1960/1969) — como operações possíveis entre o significante e o gozo.

Em “O aturdito" (1972/2003), Lacan opõe o princípio da inexistência da relação sexual, que derroga a contradição ao princípio de não contradição de Aristóteles. O novo princípio da inexistência da relação sexual, que opera a partir do dito e do dizer, pode estar relacionado com a interpretação poética proposta por Lacan, que situa o real como o fora do sentido com o qual a interpretação opera, que é a prática psicanalítica. Esse real é o ponto de fuga como o próprio objeto da ciência como uma ideia-limite, que é abordada pela psicanálise, como Lacan apresenta na Conferência de Bruxelas:

Que a psicanálise não seja uma ciência, isso cai por seu próprio peso, inclusive é exatamente o contrário. Isso cai por seu próprio peso se pensamos que uma ciência não se desenvolve mais que com pequenas mecânicas, que são as mecânicas reais, e que, apesar de tudo, há de se saber construí-las. Por isso é que a ciência tem todo um lado artístico, é fruto da indústria humana, e há de se saber fazer ali. Porém, esse saber fazer ali desemboca no plano de chiqué. O chiqué é o que habitualmente se chama Belo. (...) Talvez a ciência tomasse outro giro se se fizesse uma trama, isto é, algo que se resolvesse em fios. ${ }^{1}$ (Lacan, 1977, pp. 3-4, inédito)

Nesse ponto, Lacan faz referência à mostração presente na topologia do nó borromeano, o qual traz o real enodado com os registros do simbólico e do imaginário, além de situar-se como o fora do sentido. O nó borromeano mostra o espaço do ser falante, do sujeito, o qual é foracluído pelo discurso da ciência.

É o que aborda com o conceito de more geométrico, no qual se deteve no seminário Les non-dupes errent (1973-1974, inédito), com o objetivo de circunscrever a

1 No original: "Que el psicoanálisis no sea una ciencia, eso cae por su propio peso, incluso es exactamente lo contrario. Esto cae por su propio peso si pensamos que una ciencia no se desarrolla más que con pequeñas mecánicas que son las mecánicas reales, y que a pesar de todo, hay que saber construirlas. Por eso es que la ciencia tiene todo un costado artístico, es un fruto de la industria humana, y hay que saber hacer allí. Pero este saber hacer alli, desemboca en el plano de chiqué. El chiqué es lo que habitualmente se llama de Belo. (...) Tal vez la ciencia tomaría otro giro si se hiciera una trama, es decir algo que se resuelva en hilos." 
causa da forma que está em relação ao corpo e ao gozo. No entanto, não se trata de um corpo anatômico, mas de um corpo falante, o qual se reproduz a partir uma falha, a partir da equivocidade mediante o mal-entendido de seu gozo e do real. Foi por isso que Lacan também criou o conceito de objeto $a$ para abordar o real e a equivocidade proveniente desse objeto. A equivocidade comparece sempre às custas do objeto $a$, e o falo se apresenta como aquilo que não permite o equívoco, pois fecha uma significação e verdade absolutas, a significação fálica. Então, a interpretação produz efeito de sentido e vai contra o valor de verdade.

Torres (2012) ressalta que essa formalização, também empreendida no seminário Encore (1972-1973/2010), aponta para a interpretação que é orientada por um dizer que não visa à verdade, ao menos em sua vertente toda. Desse modo, Lacan circunscreve a interpretação em relação ao não sentido ao resistir à manutenção da significação fálica em direção a não sustentar uma verdade atrelada ao ser do sujeito, mas, sim, em direção à falta-a-ser em sua divisão. Também é endereçado ao ser-para-o-sexo pela incidência da substância gozante.

Ao empreender uma separação entre dito e dizer, Lacan situa a verdade do lado do dito, mas em sua possibilidade de ser semidita. É nessa impossibilidade de ser dita toda que a relação sexual não se escreve e que a fantasia fundamental é montada como resposta ao real. O que endereçará, no caminho de uma análise, ao que Lacan (1976/2003) nomeou verdade mentirosa (Torres, 2012), a qual pode ser verificada pelo dispositivo do passe proposto como demonstração do impossível.

O passe é o que separa o objeto $a$ da hiância da castração que obtura ou, mais propriamente, evidencia a escrita da fantasia, a qual serve para obturar a castração. Em "O aturdito" (1972/2003), Lacan aborda o passe, mesmo que essa palavra não esteja presente no escrito, como o corte, como uma operação topológica do dizer da interpretação, corte esse que, a partir da dupla volta, fecha a repetição infinita da demanda no toro neurótico. A partir desse corte operado pela interpretação do dizer, temos a queda do objeto $a$, o que reduz o sujeito a um ser sem substância, levando ao luto do objeto $a$ ou à posição depressiva própria ao final de análise. Há uma estrutura modificada pelo corte que denota o fim de uma análise e demonstra um cálculo topológico em que ocorre uma costura desse corte para endereçar o sujeito à satisfação. Esse dizer da interpretação que faz passe e produz corte também faz nó e se manifesta como um efeito do final de análise (Bousseyroux, 2011). Trata-se de uma travessia da fantasia em que o objeto $a$ passa a ser dedutível e algo pode ser inventado a partir do furo da causa, verdade material, no lugar da neurose, verdade como causa material, o que Lacan articula em "A ciência e a verdade" (1966/1998).

Assim, o que não é dito não comparece como da ordem da verdade, mas da ordem do real, de modo que o dizer é orientado pelo real, esse que está posto des- 
de o início da análise e que é interrogado pelo passe, o qual surge do impasse da fantasia. Aí se reconhece uma lógica formal que foi utilizada para formalizar esse real e estabelecer um laço pela via do discurso do analista, como bem apresentou no seminário O avesso da psicanálise (1969-1970/1992), em que pode ser operada a interpretação a partir da lógica e da palavra que possa suspender o sentido e ir contra a significação.

E como é possível nos orientarmos no inconsciente real de lalíngua, o qual não se endereça ao dicionário e nem à direção da sintaxe? Como é possível essa orientação sem um retorno à representação, o que Lacan nomeia escroqueria (Bousseyroux, 2011)?

Como já abordamos, Lacan recorre à noção de matema e à literalização para se guiar no inconsciente real, pois afirma que somente a matematização é capaz de apreender o real. Por isso nos traz o final de análise e o passe como o momento de demonstração do impossível, como a tentativa de provar o real como impossível. Também por esse motivo Lacan abordou os três impossíveis da matemática. O primeiro é o impossível de demonstrar a partir do teorema da incompletude de Gödel, o qual vale para o inconsciente como linguagem, mas não para o inconsciente real. O segundo impossível foi o exemplo do matemático Cantor, que, diante do impossível de enumerar a partir do número não contável, criou o real matemático do contínuo: "o inumerável seria o segundo Aleph que viria suceder imediatamente, em um salto e sem perda, ao primeiro Aleph, este enumerável" (Bousseyroux, 2011, p. 4), hipótese que jamais chegou a demonstrar. E, como o terceiro impossível, temos o real woodiano, que é o impossível do real ser um todo e constituir um universo, o que Lacan formalizou como lado direito das fórmulas da sexuação, em que o não-todo está articulado com o quantificador da existência como negado, de tal modo que, como Bousseyroux (2011, p. 3) comenta, Lacan sustentava que "o psicanalista não se manteria nada menos que à altura do impossível que o matemático demonstra". Trata-se do aparecimento de uma escrita do real como impossível a partir de um evento do dizer, ou seja, é a partir da contingência que o impossível se demonstra e que o real se torna ex-sistente. Que algo seja impossível não o faz impossível de se escrever, então algo cessa de não se escrever pela via da contingência e demonstra-se o impossível.

No entanto, em Lacan verifica-se uma aproximação do real para além da demonstração do impossível, que é a mostração a partir da topologia. Essa mostração comparece a partir do que Lacan nomeia ab-sens, sens blanc (sentido branco), o que é homófono a semblant (aparência), o que nos traz o real fora da semântica, oferecendo maior peso ao sentido em detrimento da significação. O significante assemântico é um limite ao simbólico, como no caso do pai real da horda primitiva, o qual constitui o quantificador da exceção nas fórmulas da sexuação, que faz 
limite ao universal do todo fálico. Esse significante no real produz o sujeito como resposta do real, o que nos indica o inconsciente como real. Isto é, o real comparece como o furo do simbólico e que faz limite à verdade mentirosa da fantasia.

Essa resposta diz respeito ao corte e ao furo como mostração em detrimento da demonstração. $O$ corte que produz uma suspensão de sentido e faz furo não permite que o analisante se apoie em uma pontuação de final de sessão como uma "boia de sentido" (Bousseyroux, 2011), mas que haja uma separação do Um do significante de modo a não poder ser atribuído a um sujeito, diversamente da escansão, a qual destaca o Um do sentido ou uma unidade semântica. Aqui, estamos diante do impredicável ou do impossível de predicar, que mostra o furo do real do inconsciente real, o qual se manifesta em detrimento do inconsciente como linguagem que se demonstra, e, por isso, Lacan não recorreu apenas à lógica para tal empreendimento. Recorreu também à topologia borromeana a partir da mostração para abordar o furo do inconsciente real que se manifesta, o que nos diz que não existe mostração sem demonstração e sustenta a relação entre a lógica e a poética na interpretação lacaniana.

Assim, pode-se afirmar que a aproximação lógica do real é um passe pelo impossível e que a aproximação topológica do real é um passe pela realização do corte, esta como uma aproximação do real pela via do poema com um passe pelo étrou (éfuro/seronde), no que está em jogo não mais a demonstração, mas a mostração.

É, então, que Bousseyroux (2011) interroga como é possível não preencher o furo, que religião e lógica, com a demonstração, tentaram preencher com o sentido. É no seminário L'insu que sait de l'une-bévue s'aile à mourre (1976-1977, inédito) que Lacan recorrerá à interpretação pela via poética em detrimento da lógica para produzir o esperado efeito de furo e suspensão de sentido para tocar o real.

Lacan acrescenta que o sujeito que solicita uma análise se alfabetistifica, pois está em jogo a bêtise, a besteira ou tolice do inconsciente, o que se transmite pelo equívoco. É que aborda quando produz a homofonia entre os não-tolos erram e os Nomes-do-pai, de modo a apontar o caminho da interpretação pela equivocidade como o caminho para uma análise. E para essa interpretação não emprestar um terceiro ao furo [ne pas un tiers prêter au trou], homófono a não interpretar o furo [ne pas interpréter au trou], é necessário que a interpretação seja ateia para não permitir que um terceiro sopre o sentido pelo furo (Bousseyroux, 2011) e mantenha-o como efeito de suspensão de sentido. Lembremos que, por ocasião do envio do livro sobre a escritura poética chinesa, de François Cheng, que influenciou sobremaneira Lacan, este lhe envia uma carta, na qual afirma: "eu o digo: a partir de agora, toda linguagem analítica deve ser poética”.

Para abordar a operação analítica pela via da interpretação, recorremos a Bousseyroux (2013), quando ele nos apresenta aquilo que chama "os três estados 
da palavra”. Assim como a matéria apresenta três estados, a palavra também os apresenta. Porém, estes não são nem físicos, nem psíquicos, mas, sim, topológicos, quais sejam: a palavra vazia, a qual remete à significação fálica, a palavra plena, que se refere à duplicidade de sentidos e ao indecidível, e a palavra poética, que suspende o sentido. É o estado da palavra poética que nos interessa analisar neste momento, à medida que passa a ter uma importante função para a clínica psicanalítica a partir de Lacan.

Em diversos momentos de sua obra, o psicanalista faz referência à poesia, demonstrando o estilo que já estava sendo delineado antes mesmo do início de seu ensino nos anos 1950. No entanto, para entender o que o autor articulou sobre a poesia, devemos, primeiramente, compreender o que ele diz sobre a palavra, para, posteriormente, compreender o que aborda sobre um de seus estados, a palavra poética.

No seminário Os escritos técnicos de Freud (1953-1954/2009), Lacan nos diz que a palavra ou o conceito é a palavra em sua materialidade e articula que se trata da própria coisa, ou seja, a palavra é a coisa. Além disso, articula a palavra como algo que se desloca na dimensão da verdade: "a palavra, desde que se instaura, se desloca na dimensão da verdade. Só que a palavra não sabe que é ela que faz a verdade. (...) é em relação à verdade que se situa a significação de tudo que é emitido" (Lacan, 1953-1954/2009, p. 295).

A palavra, ao remeter à verdade, ultrapassa aquele que a enuncia; e isso diz respeito ao enunciado e à enunciação. Ao se indagar sobre a estrutura dessa palavra, que está para além do discurso, ressalta seus três movimentos dialéticos: a Verdichtung, a condensação, a Verneinung, a negação, e a Verdrängung, o recalque, como o único movimento que interrompe a fala, posto que nele faltam palavras ao falante.

Ao fazer referência à Verdichtung, Lacan nos diz que ela

(...) se mostra não ser mais que a polivalência dos sentidos na linguagem, seus acavalamentos, seus recortes, pelos quais o mundo das coisas não é recoberto pelo mundo dos símbolos, mas é retomado assim - a cada símbolo correspondem mil coisas, a cada coisa, mil símbolos. (Lacan, 1953$-1954 / 2009$, p. 305)

Segundo Garcia (2010), Lacan elaborará o conceito de metáfora, como a função primordial do significante, a partir da Verdichtung. Dichtung, sem o prefixo Ver, corresponde ao ato de versejar, poetizar, mas também pode significar apertar, assim como Dräng, que remete à Verdrängung. Desse modo, podemos articular que o recalque não o é sem a condensação. 
A etimologia da palavra Dichten diz respeito a compor uma obra de arte oral ou falada. Dichter significa poeta, enquanto Ver corresponde ao ato de comprimir algo em uma língua, sendo um prefixo que pode ser utilizado na formação de substantivos e adjetivos ou na formação com verbos (Oxford \& Duden, 1985 citado em Garcia, 2010). Jakobson (1960/1969) afiançará que a poética está articulada com o problema: o que faz de uma linguagem verbal uma obra de arte? O objeto principal da poética seriam as differentia specifica entre a arte verbal e as outras artes e espécies de condutas verbais.

Ainda no seminário Os escritos técnicos de Freud (Lacan, 1953-1954/2009), Lacan anuncia que a palavra só comparece no discurso a partir da regra fundamental da associação livre, posto que suspende o princípio de não contradição aristotélico e o que foi exposto acerca do estatuto da enunciação a partir do ne explétif. Nesse caso, Lacan postula que, à medida que essa palavra é revelada, ocorre a realização do ser, que só existe virtualmente, o que, posteriormente, coaduna-se com a formulação de que o sujeito é produzido somente em análise.

Partimos do enunciado de Lacan de que a psicanálise pode utilizar-se da homofonia em direção ao equívoco quando lhe convém e empreende um diálogo com Jakobson (1960/1969) em suas investigações acerca da função poética da linguagem.

De acordo com Gianesi (2016), Lacan articulava o equívoco, que é produzido pela função poética, entre os Nomes-do-pai e os não-tolos erram, afirmando, no seminário Les non-dupes errent (1973-1974, inédito) que nos dois termos se encontrava o mesmo saber, esse que se encontra no inconsciente e do qual o sujeito pode decifrar-se, pois a decifração mantém o enigma. O discurso do analista é que o permite essa decifração, pois aponta para o sintoma como contradição - na qual se pode localizar o equívoco - e para a verdade não-toda, de modo a abrir a significação para o indecidível, por suspender o sentido com o uso da palavra poética.

Em seu estilo, Lacan fez uso da palavra poética, como já destacamos. Talvez por isso a queixa de muitos de que não se fazia compreender. Em 1929, ele escreveu um poema chamado Hiatus irrationalis, no qual há um verso que diz: "Mas, se todos os verbos na goela definham/ Coisas, vindo do sangue ou da forja tenham,/ Natureza - no fluxo elemental vagueio", ou "No cego e surdo mal, no deus de senso findo". Nesse momento, parece que ele já está falando da insuficiência da palavra para dar conta do sentido, ou, como nos diz Bousseyroux (2013, p. 4), "que prelúdio, que presságio assim se profere! Hiatus irrationalis, hiato de um sem razão, hiância de um extrassenso, o esp de um laps - é bem isso o inconsciente do qual, bem mais tarde, Lacan reinventará o real”. Além disso, articula esse esp de um laps com a verdade. 
No mesmo ano em que publica Hiatus irrationalis, há a publicação de seu artigo intitulado "O problema do estilo" na revista surrealista e batailleana Minotaure, no qual fala de uma possível solução teórica para o problema do estilo, incluindo o do artista. Com esse exemplo de articulação, Bousseyroux (2013) assinala que podemos conceber o estilo lacaniano como poético, diferentemente do de Freud, que se apresentava como romanesco - pois este estava mais interessado no romance narrativo e na ficção mitológica —, de modo que seria possível Freud dizer de si "eu sou um mito ou eu sou um romance".

Esse estilo poético, para Lacan, seria indispensável para a psicanálise, o que é demonstrado pelas várias referências que faz à poética em sua obra. Além disso, Bousseyroux (2013) apresenta-nos a questão sobre a possibilidade de uma solução teórica por meio da topologia para o estilo poético lacaniano.

Retomemos o Prefácio à edição inglesa do Seminário 11:

Quando o esp de um laps - ou seja, visto que só escrevo em francês, o espaço de um lapso - já não tem nenhum impacto de sentido (ou interpretação), só então temos a certeza de estar no inconsciente. O que se sabe, consigo. (...) Restaria o fato de eu dizer uma verdade. Não é o caso: eu erro. Não há verdade que, ao passar pela atenção, não minta. (Lacan, 1976/2003, p. 567)

Nesse prefácio, entendo que Lacan tenta abordar o ab-senso ou o fora de sentido presente no inconsciente. Ao fazer referência ao "esp de um laps", ou ao "espaço de um lapso", fala-nos de um limite na interpretação imposto pelo fora de sentido do real no inconsciente. Além disso, traz a referência à verdade mentirosa que pode ser verificada pelo passe.

Ainda nesse mesmo texto, Lacan, ao abordar o ab-senso no inconsciente, toca na questão da verdade, ao afirmar: "Não há verdade que, ao passar pela atenção, não minta." Essa verdade mentirosa remete ao paradoxo do mentiroso. Tal paradoxo consiste no seguinte: quando o mentiroso diz "eu minto", já está dizendo a verdade e, dessa forma, não mente. Assim, mesmo que nos deparemos com a mentira implicada com a verdade, não desistimos de persegui-la, de correr atrás de uma verdade que é não-toda.

Lacan diz: "não sou um poeta, mas um poema. E que se escreve, apesar de ter jeito de ser um sujeito" (Lacan, 1976/2003, p. 568). Ao afirmar "não sou poeta, mas um poema”, não está querendo dizer "eu sou próprio à identificação ao sintoma”, como aquilo, de acordo com Bousseyroux, "que tangencia a relação nativa do falasser com 'lalíngua”' (Lacan, 1976/2003, p. 6). Lacan, ao dizer que não é poeta o suficiente, mas, sim, poema, faz referência a uma questão topológica, e não on- 
tológica, afirmando que seu poema assinado como Là-quand, que brinca com a homofonia em relação a seu nome próprio, indica o significante como índice que responde ao real.

Em um folheto enviado a Jean-Michel Vappereau, verifica-se um maior desenvolvimento dessa questão iniciada no Prefácio à edição inglesa do Seminário 11 (1976/2003), ao iniciar com a afirmação de que nasceu poema e papouète e acrescentar que, do poema de Lén-Paul Fargue, do qual retira os significantes para construir papouète, podem-se extrair histórias engraçadas, em que o mais curto seria o melhor. Isso as aproxima do chiste, tal como um poema-Witz (chiste), que produz furo no real. Assim, construiu sua assinatura $L \grave{a}$-quand, que não remete a nenhuma garantia ou selo e por isso se apresenta como ateia e antirreligiosa, com a qual teria se submetido ao passe.

Isso pode dar indicações do que em lalíngua é poema, por ser a intercessora do saber inconsciente, visto que não ascende ao $S_{1}$, mas possibilita operar sobre o Um encarnado em lalíngua, indicando que aí se goza. "Lalíngua nos faz nascer poema”, fala-nos Bousseyroux (2013). Ao nascermos, somos poema como falasser. No entanto, não há ainda poeta, pois o que se apresenta é o saber sem sujeito do insconsciente - lalíngua. Trata-se de um poema sem sujeito.

A afirmação de que não é um poeta, mas, sim, um poema, está relacionada, como já destacamos, com o estilo de Lacan, o qual recorre à interpretação poética pela via da função poética da linguagem, estabelecida por Jakobson (1960/1969), com o objetivo de, a partir do equívoco, recurso muito utilizado pelos poetas, operar de modo a suspender o sentido na experiência de análise.

Segundo Bousseyroux (2013), Lacan nos diz que Léon-Paul Fargue apresenta-nos o desejo de que sejamos não não-poeta (pas papouète). Este apresenta, em seu poema, significantes assonantes de lalíngua, com grupos de fonemas homófonos, poésie, pouasie, papou, papouasie, condensando-se e produzindo um novo sentido: pas papouète. Essa dupla negação tem uma decorrência que introduz o efeito de não sentido e um sentido novo: "não não-poeta" (pas papouète), operando com a sonoridade de lalíngua, trazendo-nos que o que sobra é somente o "piu" do significante (Bousseyroux, 2013, p. 7), como uma suspensão do sentido, um sentido branco (sens-blanc), o que tem íntima articulação com a função poética.

Bousseyroux (2013) articula, a partir de Jakobson, que essa função estaria ancorada na função senso-determinativa do som e que as sonoridades têm papel preponderante na estruturação do poema. Os sons, que seriam traços distintivos da língua, teriam a função de discriminar o sentido; no entanto, haveria também outra função do som, a de determinar o sentido, transpondo os dualismos da língua, quais sejam: o dualismo do signo linguístico entre significante e significado, e entre signo e referente; e o dualismo entre o eixo paradigmático da metáfora 
por substituição e o eixo sintagmático da metonímia por contiguidade, dualismos que são mantidos com a primeira função discriminativa do sentido. $\mathrm{O}$ segundo dualismo possibilita que sejam assinaladas a similitude e a não similitude de duas unidades verbais dotadas de sentido, impedindo a ambiguidade da língua a partir do uso da homofonia.

Segundo Bousseyroux (2013, p. 9), essa determinação poética do sentido ocorreria a partir das possibilidades fônicas da língua, valendo-se das figuras de equiparação fônica, como a paronomásia, o anagrama, a onomatopeia e a sinestesia, considerando que apareceria um efeito de sentido, partindo da tensão entre sentido e som, como "a atualidade dos fatos do real de lalíngua, e não o efeito da retração temporal do significante no simbólico". Quer dizer, Lacan recorreu à função poética, tal como formulada por Jakobson, mas introduziu lalíngua como o que traz a dimensão do real da linguagem, o que pode ser exemplificado quando diz que nascemos poema como falasser e não poeta, pois o que se tem é um saber sem sujeito do inconsciente - lalíngua, possibilitando que se opere com a suspensão do sentido pela palavra poética.

Para Haroldo de Campos (2000), a emergência da função sonora em detrimento da queda da função referencial da poesia pode destacar o descobrimento da palavra astro no adjetivo desastrado ou no substantivo desastre, de modo que o poeta produz equívocos calculados, que produzem tensão entre som e sentido, a partir dos quais o analista pode servir-se em sua interpretação. Esse procedimento é próximo também à investigação anagramática empreendida por Saussure (2012 citado em Gianesi \& Ramos, 2015), em que fazia operar um jogo fônico análogo ao jogo da poesia chinesa (Campos, 2000) e apresentava a variedade de sentidos e o cúmulo de sentido, o que endereça à verdade não-toda, pois vai contra a significação.

Dessa maneira, Lacan levanta o problema do duplo sentido, que possibilita que se diga a verdade através da mentira sem ser um mentiroso, pois essa duplicidade de sentido é própria ao significante, de modo que comparece na poesia relacionada com a metáfora. Esse ponto apresenta a questão da hermenêutica, pois possibilita que a interpretação vá além do dito pela via do dizer.

Lacan, interessado que era pela palavra poética, recorreu ao chinês e ao ideograma para conhecer a poesia chinesa, como já destacamos. Aprenderá a língua chinesa durante a Segunda Guerra, antes da reforma maoista da escrita chinesa. A principal referência lacaniana é a escrita tradicional, a qual se apresenta mais concisa e com o uso de um menor número de caracteres ideográficos, o que estava em consonância com seu interesse pela homofonia e pela equivocidade da palavra poética (Andrade, 2016).

Destaca-se a operação lógica de furo, com o dito da fala do analisante, e corte, a partir da interpretação pelo dizer do analista, que produz suspensão de sentido, 
operando um deslizamento da palavra vazia e da palavra plena à palavra poética, pois, se acompanharmos Lacan (1976-1977), a interpretação visa ao sentido e vai contra a significação, a significação fálica que sustenta um valor de verdade para a fantasia do sujeito, o qual é traduzido em forma de sintoma como resposta do real.

\section{Referências bibliográficas}

Andrade, C. (2016). Lacan com François Cheng. Revista Derivas Analítica, Belo Horizonte, 5. Recuperado de http://revistaderivasanaliticas.com.br/index. php/cheng

Bousseyroux, M. (2011). Au risque de la topologie e de la poésie: élargir la psychanalyse. Toulouse: Eres. Coleção Point Hors Ligne.

Bousseyroux, M. (2013). Os três estados da palavra: topologia da poesia. Conferência ministrada na Universidade de São Paulo, São Paulo, Brasil. Inédito.

Campos, H. (2000). Ideograma, anagrama, diagrama: uma leitura de Fenollosa. In H. Campos. Ideograma: lógica, poesia, linguagem (4a ed., pp. 23-108). São Paulo: Edusp.

Garcia, M. G. (2010). Da metáfora ao literal: Jacques Lacan com Arnaldo Antunes. (Tese de doutorado, Programa de Pós-graduação em Psicologia Clínica). Pontifícia Universidade Católica do Rio de Janeiro, Rio de Janeiro, RJ.

Gianesi, A. P. (2016). Constelações clínicas. In A. P. L. Gianesi, B. H. M. Almeida, \& Vogellar, R. B. (Orgs.), Rede Clínica (pp. 45-58). São Paulo: Escuta/Fórum do Campo Lacaniano.

Gianesi, A. P., \& Ramos, C. (2015). Anagrama e ideograma na associação e interpretação psicanalíticas. Apresentado no Simpósio Interamericano da Internacional dos Fóruns do Campo Lacaniano (IF) e sua Escola de Psicanálise dos Fóruns do Campo Lacaniano (EPFCL): A outra cena. A voz e o olhar na experiência analítica e na arte. São Paulo, SP, Brasil.

Jakobson, R. (1969) Linguística e poética. In R. Jakobson. Linguística e comunicação (pp. 118-162). São Paulo: Cultrix. (Trabalho original publicado em 1960)

Lacan, J. (1973-1974). Les non-dupes errent. Inédito.

Lacan, J. (1976-1977). L'insu que sait de l'une bévue s'aile à mourre. Inédito.

Lacan, J. (1977). Conferência de Bruxelas. Inédito.

Lacan, J. (1992). O seminário, livro 17: o avesso da psicanálise. (Ary Roitman, Trad.).

Rio de Janeiro: Jorge Zahar. (Trabalho original publicado em 1969-1970)

Lacan, J. (1998). A ciência e a verdade. In J. Lacan. Escritos (pp. 869-892). (Vera Ribeiro, Trad.). Rio de Janeiro: Jorge Zahar. (Trabalho original publicado em 1966) Lacan, J. (2003). O aturdito. In J. Lacan. Outros escritos (pp. 448-497). (Vera Ribeiro, Trad.). Rio de Janeiro. Jorge Zahar. (Trabalho original publicado em 1972) 
Lacan, J. (2003). Prefácio à edição inglesa do Seminário 11. In J. Lacan. Outros escritos. (Vera Ribeiro, trad.) (pp. 567-569). Rio de Janeiro: Jorge Zahar. (Trabalho original publicado em 1976)

Lacan, J. (2009). O seminário, livro 1: os escritos técnicos de Freud. (Betty Milan, Trad.). Rio de Janeiro: Jorge Zahar. (Trabalho original publicado em 1953-1954)

Lacan, J. (2010). Encore. Escola Letra Freudiana. Edição não comercial destinada exclusivamente aos membros da Escola. (Trabalho original publicado em 1972-1973)

Torres, R. (2012). O que pode ser uma lógica do real? Stylus: Revista de Psicanálise, Rio de Janeiro, 24, 85-92.

Recebido: $22 / 08 / 2018$

Aprovado: 10/10/2018 